\title{
Understanding Gas Vesicles and Its Scope in Biotechnological Applications
}

\author{
Priya Upadhyay ${ }^{1}$, Amogh Nagarkar², Dhiraj Jain ${ }^{2}$ and Annamma Odaneth ${ }^{1 *}$ \\ ${ }^{1}$ Department of DBT-ICT Centre for Energy Biosciences, Institute of Chemical Technology, India \\ ${ }^{2}$ Department of Chemical Engineering, Institute of Chemical Technology, India
}

Submission: August 10, 2018; Published: September 12, 2018

*Corresponding author: Annamma Odaneth, Department of DBT-ICT Centre for Energy Biosciences, Institute of Chemical Technology, Nathalal Parekh Marg, Matunga, Mumbai, India, Email: a.dbtceb@gmail.com

\begin{abstract}
Gas vesicles are gas permeable membrane bound proteinaceous organelles forming integral parts of the gas vacuole. These vesicles are found in various microbes and play an important role in buoyancy, thereby enabling them to adapt to various environmental conditions. A peculiar feature of this vesicle is the homologous nature with respect to membrane protein across various microorganisms. Its synthesis is mediated by gvp gene cluster where GvpA is the main structural protein forming the core vesicle and is highly conserved while GvpC is another supporting protein providing the strength to the vesicle. The group of Gvp proteins can be easily targeted for genetic manipulations enabling gvp gene cluster to be engineered to enable different protein associations or entrapments. Numerous applications that require enhanced oxygen transfer rate in bacterial/yeast/fungal/mammalian cell cultures, ultrasound imaging, antigen presentation, drug delivery system and vaccine development can be attempted by modifying the gene cluster as a "BioBrick" enabling engineering microbes for better functionalities and also engineering localization of proteins/enzymes for in vivo immobilizations.
\end{abstract}

\section{Gas vesicle and its importance}

Gas vacuoles comprise of aggregates of gas vesicles which is also known as hollow bodies, aerosomes, pseudo vacuoles and floatation bodies [1]. These vesicles are small, inert, low density and hollow gas filled proteinaceous intracellular organelles found in several microbes such as cyanobacteria, proteobacteria and archaea which imparts them with selective advantages for environmental adaptation [2]. In case of cyanobacteria, these gas vesicles facilitate buoyancy that helps in regulating positions at favourable depth for photosynthesis and for growth in aquatic environment. For haloarchaea, gas vesicle provide buoyancy so that bacteria can move towards oxygen-rich surface areas in hypersaline environments and for energy (ATP) synthesis driven by light-driven proton pump bacteriorhodopsin. In heterotrophic bacteria, gas vesicle act as light-shielding organelle against the high light intensity and can provide larger surface to volume ratio for nutrient acquisition in order to adapt to low temperature conditions [3].

Gas vesicle membrane is solely composed of proteins and devoid of other biomolecules like lipids and carbohydrates [4]. Moreover, these proteins are homologous in nature whose production and regulation are controlled by gvp gene cluster encoding 8 to 14 Gvp proteins found both chromosomally and on plasmid DNA [4,5]. From amino acid sequencing it was found that GvpA is a small 7-8 $\mathrm{kDa}$ hydrophobic protein corresponding to the major component of the ribbed vesicle while the GvpC is a large 20-40 kDa hydrophilic protein present externally on the vesicle to stabilize it against the external pressure, while it does not have important role in membrane integrity $[2,6]$. These vesicles are freely permeable to gases, water molecules are excluded from the interior compartment due to the hydrophobicity of the membrane protein. It has a defined shape where small biconical structure polymerises in a particular fashion to form spindle or cylinder shape and can withstand several bars pressure until it reaches certain critical pressure $[2,4,5]$. Gas vesicle of cyanobacteria can withstand more pressure as compared to halobacteriaceae which is due to difference in GvpA protein secondary structure, particularly $\beta$-strand orientation [3]. Similarly, they differ in their net negative charge; species habituating in higher ionic strength environment shows greater negative charge on GvpA protein [7]. Thus, the mechanical strength of gas vesicle is defined by its dimension/shape and the way by which proteins are arranged [2].

Protein GvpA is highly conserved across the various microbial domains. According to secondary structure prediction, GvpA protein is comprising of two $\alpha$ helices $(\mathrm{H} 1, \mathrm{H} 2)$ separated by two antiparallel $\beta$ strands (coil- $\alpha$ helix $-\beta$ strand $-\beta$ strand- $\alpha$ helixcoil) peptide backbone $[2,4]$. Any mutation in $\mathrm{H} 1 \alpha$-helix results in inability of the protein to form a vessicle while the substitution of Gly33, Ile34 or Glu35 amino acids results in altered shape and property of the vesicle [4]. In a study carried out on gvp gene cluster, it was found that dimension and property of the gas vesicle solely does not depend on GvpA, rather it is an interplay 
of two or more gvp gene products [6]. For example, GvpJ and GvpM protein are highly similar to $\mathrm{H} 1$ of GvpA indicating an important but still unexplained role in vesicle biogenesis [4]. GvpC is another hydrophilic protein with repeated 31- 38 amino acids residues in $\alpha$-helices, that are highly conserved in cyanobacteria and less conserved in haloarcheae [2].

Gas vesicle synthesis and its regulation are driven by the differential expression of gvp gene clusters, often influenced by several environmental parameters. In cyanobacterium, Calothrix sp. PCC 7601, gvp gene expression is mediated by light-dependent antisense RNA regulation [8]. In Halobacterium species, gas vesicle synthesis regulation is affected by oxygen tension and is thereby regulated by GvpD and GvpE protein where GvpD is involved in suppressing the expression of GvpA; GvpC while GvpE protein is involved in the expression of the GvpA and GvpC [9]. Serratia sp. ATCC 39006, contain 19 genes cluster which are responsible for gas vesicle synthesis and is dependent on cell density controlled by quorum-sensing locus SmaIR, regulating quorum sensing signalling molecule $\mathrm{N}$-acyl homoserine lactone synthesis which acts via direct transcriptional repression of gvpA1 operon [10]. Gas vesicle regulator proteins such as GvrA and GvrB act as regulator under nutritional stress condition whereas GvrC represses expression of the gvp gene cluster in presence of flagella. The gvp gene clusters are observed in other microbes such as Bacillus megaterium and Streptomyces coelicolor but gas vesicles are not observed in these microbes [11]. Presence of the gas vesicle in these organisms still remains unclear.

\section{Biotechnological applications}

Gas vesicles are produced by various microbes which can be easily purified and can be used as nanoparticles (GVNPs). GvpC protein which is found on the gas vesicle surface has a specific region (C-terminal) in which a gene cluster can be inserted, leading to formation of Gas Vesicle Nano-Particles (GVNP) [12]. These GVNP due to their nanoscale size can be used for effective drug delivery and platform for vaccine development [12]. The GVNP obtained from Halobacterium sp. NRC-1 can be used for intradermal/transdermal delivery of protein or peptide derived drugs [13]. SopB4-GVNPs derived from Halobacterium sp. NRC-1 is used for vaccine development against Salmonella enterica antigens [14]. Endotoxic shock treatment has been evaluated in mice by fusing murine bactericidal/permeabilityincreasing protein (mBPI) to GvpC protein resulting in mBPINGVNPs which has shown promising results [15]. Gas vesicles treated with glutaraldehyde is used in cell culture system to provide better oxygen supply as these vesicles has high oxygen carrying capacity [16]. Gas vesicle was genetically engineered to obtain acoustic nanomaterial which has potential applications in ultrasound imaging [17]. Moreover, these vesicles can find numerous applications in bioremediation of oil spills, flotationbased separation, and purification of specific molecules from the mixtures which are currently unexplored.

\section{Summary}

Membrane bound organelle such as gas vesicles are found in various microbes as it imparts them advantages under various environmental stressful conditions. Biogenesis of gas vesicles involves interplay of Gvp proteins from the gvp operon, apart from the major structural protein, GvpA. There are several environmental parameters that affect the gas vesicle synthesis by regulating the gvp operon and thereby, the composition and the nature of proteins expressed and so the final gas vesicle formed. In lieu of the natural adaptions, gas vesicles offers an excellent platform to be engineered systematically for various biological applications. With the advent of new technologies, baby steps for specific biological applications have started to appear, however there is a huge scope and the area is widely unexplored.

In a more practical way, local waste can be valued without spending enough money. How to neglect this opportunity at the expense of chemical fertilizers? This is the place to interpret the different actors of the agricultural sector for the valorization of composts for the benefit of peasant agriculture.

\section{References}

1. Walsby A E (1972) "Structure and function of gas vacuoles." Bacterial Rev 36(1): 1-32.

2. WalsbyA E (1994)"Gas vesicles." Microbiological rev 58 (1): 94-144.

3. Oren A (2013) The Function of Gas Vesicles in Halophilic Archaea and Bacteria: Theories and Experimental Evidence. Life (Basel) 3(1): 1-20.

4. Pfeifer F (2012) Distribution, formation and regulation of gas vesicles. Nat Rev Microbiol 10(10): 705-715.

5. Cai L, Zhao D, Hou J, Wu J, Cai S (2012) Cellular and organellar membrane-associated proteins in haloarchaea: Perspectives on the physiological significance and biotechnological applications. Sci China Life Sci 55(5): 404-414.

6. Offner S, Ziese U, Wanner G, Typke D, Pfeifer F (1998) Structural characteristics of halobacterial gas vesicles. Microbiology, 144(5): 1331-1342.

7. Daviso E, Belenky M, Griffin RG, Herzfeld J (2013) Gas Vesicles across Kingdoms: A Comparative Solid-State Nuclear Magnetic Resonance Study.J Mol Microbiol Biotechnol 23(4-5): 281-289.

8. Csiszàr K, Houmard J, Damerval T, Tandeau de Marsac N (1987) Transcriptional analysis of the cyanobacterial gvpABC operon in differentiated cells: occurrence of an antisense RNA complementary to three overlapping transcripts. Gene 60(1): 29-37.

9. Krüger K, Pfeifer F (1996) “Transcript analysis of the c-vac region and differential synthesis of the two regulatory gas vesicle proteins GvpD and GvpE in Halobacterium salinarium PHH4". J Bacteriol 178 (14): 4012-4019.

10. Tashiro Y, Monson R, Ramsay J, Salmond G (2016) Molecular genetic and physical analysis of gas vesicles in buoyant enterobacteria. Environ Microbiol 18(4): 1264-1276.

11. Pfeifer F (2012) Distribution, formation and regulation of gas vesicles. Nature Reviews Microbiology 10(10): 705-715.

12. DasSarma S, DasSarma P (2015) “Gas vesicle nanoparticles for antigen display." Vaccines (Basel) 3(3): 686-702. 
13. Andar AU, Karan R, Pecher WT, DasSarma P, Hedrich WD, et al. (2017) Microneedle-Assisted Skin Permeation by Nontoxic BioengineerablGas Vesicle Nanoparticles. Mol Pharm 14(3): 953-958.

14. Das Sarma P, Negi V, Balakrishnan A, Kim J, Karan R, et al. (2015) Haloarchaeal Gas Vesicle Nanoparticles Displaying Salmonella Antigens as a Novel Approach to Vaccine Development. Procedia in Vaccinology 9: 16-23.

15. Balakrishnan A, DasSarma P, Bhattacharjee O, Kim J, DasSarma S, et al. (2016) Halobacterial nano vesicles displaying murine bactericidal

This work is licensed under Creative Commons Attribution 4.0 Licens DOI: 10.19080/AIBM.2018.11.555806 permeability-increasing protein rescue mice from lethal endotoxic shock. Scientific Reports 6(1).

16. Sundararajan A, Lu-Kwang Ju (2006) "Use of cyanobacterial gas vesicles as oxygen carriers in cell culture." Cytotechnology 52(2): 139149.

17. Lakshmanan A, Farhadi A, Nety SP, Lee-Gosselin A, Bourdeau RW, et al (2016) Molecular Engineering of Acoustic Protein Nanostructures. ACS Nano 10(8): 7314-7322.

\section{Your next submission with Juniper Publishers will reach you the below assets}

- Quality Editorial service

- Swift Peer Review

- Reprints availability

- E-prints Service

- Manuscript Podcast for convenient understanding

- Global attainment for your research

- Manuscript accessibility in different formats ( Pdf, E-pub, Full Text, Audio)

- Unceasing customer service

Track the below URL for one-step submission https://juniperpublishers.com/online-submission.php 